\title{
Теоретические подходы к исследованию психологического обеспечения управления кадровой работой в научной организации
}

\author{
Елена В. Пугачева, Марина А. Войтикова* \\ Федеральное государственное бюджетное образовательное учреждение высше- \\ го образования «МИРЭА - Российский технологический университет», г. Москва, \\ Российская Федерация \\ *E-mail: marina.voytikova@yandex.ru
}

\begin{abstract}
Аннотация
Ввеление. В статье рассматривается проблема психологического обеспечения управления калровой работой в научной организации в России. Впервые проанамизированы типы научных организаций в Российской Федерации, возможности и ограничения использования в них зарубежных технологий каАровой работы в свете нарастающих процессов глобализации и информатизации в сорере научно-исследовательской Аеятельности.
\end{abstract}

Теоретическое обоснование. При выборе теоретического поАхоАа А^я организации психологического обеспечения каАровой работы важно учитывать тип научной организации в плане характера научно-исследовательской Аеятельности (теоретическая или прикладная), особенностей фринансирования (бюджетное, коммерческое, смешанное), места научно-исследовательской Аеятельности в профрессиональном поле научного сотрудника (основная и единственная или неосновная, Аополнительная).

Результаты. Проанализированы следующие теории и теоретические модели: молель пиков творческой продуктивности научного сотрудника (G.J. Feist), модель подарочной экономики в области научно-исслеАовательской Аеятельности (К. Vermeir) и гибридные молели. Проанализирована концепция мотивации научной Аеятельности Т.В. Разиной, позволяющая оценить роль Аесяти типов мотивационных субсистем в процессе осуществления научно-исследовательской Аеятельности и разработки систем ее стимулирования. Рассмотрены теоретические модели созАания творческих среА: Аинамическая теория созАания знаний в организации, разработанная колмективом исслеАователей во главе с I. Nonaka, которая может быть применима в ^юбой организации, и модель творческой среды Аля научно-исслеАовательского процесса в акалемических кругах или коммерческих научно-исследовательских ^абораториях, прел^оженная в работе A.P. Wierzbicki, Y. Nakamori. Проанализированы некоторые особенности виртуальных организаций, определяющие специфику калровой работы в них и некоторые модели осуществления этого процесса. 
пСИхолОГИЯ ТРУДА

ОбсужАение результатов. Рассмотренные зарубежные теории и теоретические поАХоАы к управлению научными комлективами проанализированы применительно к научным организациям в России. Невозможность их «прямого» использования обусловлена этнонациональной и культурной специфрикой, ограниченным использованием инорормационных технологий и отсутствием социально-экономической и политической стабильности в стране.

\section{КАючевые слова}

научная деятельность, психологическое обеспечение, калровая работа, мотивация научной Аеятельности, творческая среАа, теоретический поАХоА, творческая продуктивность, культуральная специфика, виртуальные организации, технологии

\section{Основные положения}

- многообразие типов научных организаций в России и наличие культурной и исторической специфики требуют разработки и значительной адаптации существующих приемов и технологий каАровой работы;

- перспективным представляется постепенное внедрение творческих среА в научно-исследовательские комлективы с учетом российской специфики;

- важным моментом Аля организации психологического сопровожАения каАровой работы в научных организациях России является проведение эмпирических исслеАОваний пиков творческой продуктивности и фракторов (возраст, степень и т. п.), их обуславливающих.

\section{Для цитирования}

Пугачева Е.В., Войтикова М.А. Теоретические подходы к исследованию психологического обеспечения управления кадровой работой в научной организации // Российский психологический журнал. 2018. Т. 15, № 2. С. 169-189. DOI: 10.21702/rpj.2018.2.7

Материалы статьи получены 14.02.2018

UDC 159.9.016

DOI: $\underline{10.21702 / \text { rpj.2018.2.7 }}$

\section{Theoretical Approaches to Studying Psychological Ensuring of Personnel Management in Scientific Organizations}

\section{Elena V. Pugacheva, Marina A. Voitikova*}

Russian Technological University (MIREA), Moscow, Russian Federation

*Corresponding author. E-mail: marina.voytikova@yandex.ru 


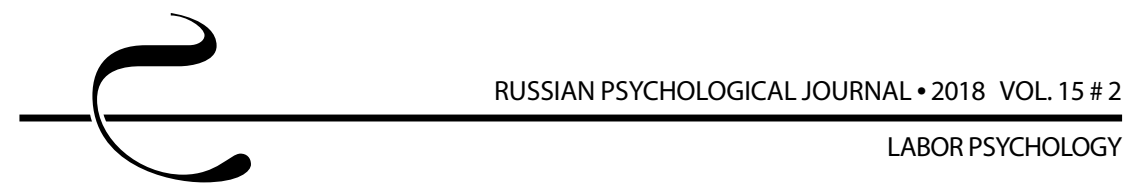

\section{Abstract}

Introduction. The paper addresses the issue of psychological ensuring of personnel management in Russian scientific organizations. For the first time, the types of scientific organizations in the Russian Federation are analyzed to account for their opportunities and limitations of employing existing international techniques for personnel management under the conditions of growing globalization and informatization in the field of research activities.

Theoretical Basis. When choosing a theoretical approach for psychological ensuring of personnel management, it is important to take into consideration the type of scientific organization in terms of its research activities (theoretical/applied), form of financing (budget/commercial/mixed), and the place the research activities occupy among a researcher's professional responsibilities (central/peripheral).

Results. The study reviewed the following theories and theoretical models: the model of the peaks of a scientist's creative productivity (G.J. Feist), the model of gift economy in the field of research activities (K. Vermeir), and various hybrid models. According to the study analyses, the concept of motivation for scientific activity (T.V. Razina) can be instrumental in assessing the role of ten types of motivational subsystems when carrying out research activities and developing the means of stimulating them. The study concentrates on the following theoretical models for establishing creative environments: (a) the dynamic theory of organizational knowledge creation (I. Nonaka and colleagues) that is applicable for any organization and (b) the model of creative environments for the research process in academic circles or commercial research laboratories suggested by A.P. Wierzbicki and Y. Nakamori. The paper also analyses certain characteristics of virtual organizations that determine specific aspects of personnel management process and reflects on particular models for its implementation. Discussion. The theories and theoretical approaches to managing research teams, encompassed in the study were analyzed specifically in application to scientific organizations in Russia. The main obstacles for their 'direct' use there lie in ethnic, national, and specific cultural characteristics of Russian research facilities, limited use of information technology, and the lack of socio-economic and political stability in the country.

\section{Keywords}

scientific activity, psychological ensuring, personnel management, motivation for scientific activity, creative environment, theoretical approach, creative productivity, specific cultural characteristics, virtual organizations, technologies

\section{Highlights}

- Cultural and historical specificity, as well as the vast variety of types of scientific organizations in Russia, determine the need for the development and considerable modification of the existing methods and techniques for personnel management. 
Gradually establishing creative environments in Russian research teams that would take into their specific characteristics has a great potential for the practice of personnel management.

- Carrying out empirical studies on creative productivity - its peaks and the factors that determine them (e. g., age, academic degree) is important for psychological ensuring of personnel management in Russian scientific organizations.

\section{For citation}

Pugacheva E.V., Voitikova M.A. Theoretical Approaches to Studying Psychological Ensuring of Personnel Management in Scientific Organizations. Rossiiskii psikhologicheskii zhurnal - Russian Psychological Journal, 2018, V. 15, no. 2, pp. 169-189 (in Russian). DOI: 10.21702/rpj.2018.2.7

Original manuscript received 14.02 .2018

\section{Введение}

Проблема психологического обеспечения кадровой работы в России на сегодняшний день стоит довольно остро. Это обусловлено недостаточным количеством отечественных подходов и разработок в данном направлении. Отечественные психологи часто привлекают для решения кадровых вопросов опыт зарубежных коллег, не адаптируя данные подходы к российским условиям. Особенно ситуация осложняется в тех организациях, которые обладают определенной спецификой как в профессиональной деятельности, которую они осуществляют, так и в ментальных установках сотрудников. В первую очередь это касается научно-исследовательских организаций.

Целью данной статьи является анализ существующих теоретических подходов и практических моделей организации различных аспектов кадровой работы в научной организации. Мы предполагаем, что как зарубежные, так и отечественные наработки в данной области могут быть использованы со значительным успехом. Однако для этого необходимо учитывать, во-первых, специфику научной организации в плане того, какое место (основное, дополнительное) занимает в ней профессиональная научно-исследовательская деятельность, во-вторых, характер финансирования данной организации (бюджетная государственная или коммерческая), в-третьих, особенности менталитета сотрудников и их актуальных ценностных ориентаций.

\section{Теоретическое обоснование}

На сегодняшний день в России можно выделить несколько типов научных организаций. Традиционно к таким организациям относятся научно-исследовательские институты, для сотрудников которых осуществление научноисследовательской деятельности - основной и зачастую единственный вид 


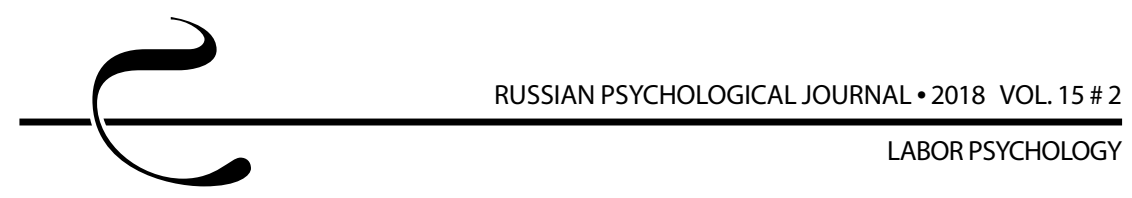

профессиональной деятельности. Вторым типом организаций являются университеты и институты, сотрудники которых по своим функциональным обязанностям также должны заниматься научно-исследовательской деятельностью, но при этом они осуществляют и преподавательскую и методическую деятельность. Надо отметить, что за последние сто лет в российских университетах акценты в осуществлении этих двух видов деятельности существенно изменились. Если в начале XX в. в России университеты были, прежде всего, научными центрами, то сейчас они выполняют в первую очередь образовательные функции. Помимо этого, в последние годы в вузах все чаще возникают некоторые промежуточные формы - малые инновационные предприятия, которые занимаются различного рода научно-исследовательской деятельностью, опытно-конструкторскими разработками под конкретные цели и задачи, создают определенные наукоемкие продукты и в ряде случаев являются не только самоокупаемыми, но и коммерчески прибыльными.

Третья группа организаций в современной России, которая занимается различными видами научно-исследовательской деятельности - это частные и коммерческие организации, лаборатории. За рубежом доля такого рода организаций (англ. Research and Development, (R\&D)) очень существенна, и при каждой крупной корпорации имеются соответствующие отделы, службы и т. п. Данные организации объединяет то, что они выполняют совокупность работ, направленных на получение новых знаний и их практическое применение при создании нового изделия или технологии. При этом за рубежом такого рода организации могут быть очень крупными, иметь огромные коммерческие прибыли, содержать большой штат научных сотрудников; многие из них являются виртуальными, имеют удаленные филиалы и отделы в самых различных странах. В России в середине XX в. такие организации также существовали при крупных производствах, однако с переходом к рыночной экономике большинство из них перестало функционировать из-за нерентабельности и неспособности адаптироваться к новым условиям. Сейчас подобная практика восстанавливается уже на коммерческой основе, однако большинство этих организаций имеют незначительные финансовые обороты, небольшой штат сотрудников и, соответственно, не обладают достаточным количеством ресурсов для проведения серьезных широкомасштабных исследований.

Все организации перечисленных типов очень условно можно поделить на такие, для сотрудников которых научная работа является основной профессиональной деятельностью, и такие, для сотрудников которых научная работа является дополнительной формой деятельности. Это, в свою очередь, определяет цели, ценности, специфику организации и работающих в ней сотрудников, а, соответственно, предъявляет особые требования к организации кадровой работы. 
Нужно отметить также определенную двойственность в организации труда в научных учреждениях и наукоемких компаниях в современной России. С одной стороны они все в большей степени перенимают модели и образцы работы зарубежных научных организаций $[1,2,3,4,5,6,7,8]$. Этому способствуют тесные международные связи, процессы глобализации, создание значительного количества совместных, межнациональных исследовательских организаций, существующих виртуально, деятельность которых осуществляется с помощью новых информационных технологий, в частности, сети Интернет. Это дает возможность использовать опыт психологического обеспечения кадровой работы зарубежных коллег. С другой стороны, в отечественных научно-исследовательских организациях сейчас присутствует несколько поколений российских ученых, которые являются носителями совершенно различных ментальных, ценностных и профессиональных установок. Эти установки обуславливают специфику их профессиональной деятельности и будут существенно тормозить внедрение зарубежных кадровых технологий, а в ряде случаев делать их полностью неприменимыми. Учет этих ментальных установок необходим при организации кадровой работы в научных коллективах.

При этом в отечественной психологии имеются свои собственные теоретические и практические наработки в области психологии управления $[9,10$, $11,12]$ и в том числе инновационными и научно-исследовательскими коллективами $[13,14,15,16,17,18,19]$.

Основными направлениями кадровой работы являются: разработка кадровой политики организации в соответствии с существующей миссией и стратегией; осуществление кадрового планирования; разработка системы показателей трудового потенциала и качества труда; создание системы найма персонала; осуществление мероприятий по адаптации персонала в ситуациях структурных и организационных изменений, а также вновь принятых сотрудников. Также кадровая работа предполагает осуществление мероприятий по диагностике актуальной мотивации персонала и на этой основе разработку систем стимулирования труда. На кадровую службу ложится задача по профессиональному развитию персонала и его карьерному росту в организации. Также кадровые службы занимаются вопросами аттестации и высвобождения персонала. Далее мы проанализируем специфику некоторых аспектов кадровой работы в научно-исследовательских организациях.

\section{Результаты}

Одной из актуальных проблем кадровой работы в науке является поиск и подбор кадров. Университеты и научно ориентированные корпорации в странах Европы и Америки сейчас испытывают острый дефицит в кадрах. 
Проблема не может быть решена только за счет научной эмиграции. Одним из путей решения проблемы научных кадров в странах со стабильной экономикой и социально-политической структурой являются различного рода программы и школы для одаренных детей. Тем не менее, вопрос о том, насколько эффективна деятельность таких школ, остается открытым. Со времен лонгитюдного исследования L.M. Terman известно, что далеко не все дети с высоким интеллектом становятся успешными взрослыми (и тем более учеными). G.J. Feist, используя метод ретроспективного лонгитюда, показывает, что подростки-финалисты конкурса «Westinghouse», как правило, в качестве профессиональной выбирали именно научную деятельность, были в ней успешны, а $83 \%$ из них получили докторскую степень [20]. При этом, чем раньше будет сделана первая публикация, тем более продуктивным впоследствии будет ученый.

Для решения задач профессионального развития и карьерного роста интересны данные, полученные G.J. Feist в отношении пиков научной продуктивности. G.J. Feist установила, что помимо пика творческой продуктивности в 20 лет (который традиционно выделял D. K. Simonton [21]), наблюдается еще один пик - примерно через 15 лет, который продолжается около 5 лет. D.K. Simonton видел причины динамики творческой продуктивности ученого в когнитивных факторах, a G.J. Feist объясняет появление первого и второго пиков социально-психологическими факторами.

Хотя разработка миссии и стратегии организации, в том числе и научной, не является целиком прерогативой кадровой службы, эти аспекты в значительной степени определяют содержание кадровой работы и ее психологическое сопровождение. В последние годы, в связи с проникновением рыночной экономики во все сферы жизнедеятельности общества, в России от науки также ждут коммерческих прибылей. Причем наличие таких прибылей становится чуть ли не основным критерием эффективности научной работы для сотрудников вузов, НИИ и т. д. Это в корне меняет психологическое содержание научной деятельности, его принципы, смыслы. За рубежом с явлением коммерциализации науки столкнулись довольно давно, и там была возможность осознать все достоинства и ограничения такого подхода.

Например, K. Vermeir [22] показывает, что влияние рыночной экономики на науку имеет скорее негативный характер. Отношение к научному знанию и научному продукту как к «товару» ведет к тому, что желание «продать товар» вытесняет внутреннюю мотивацию ученых. Это в конечном итоге может привести к тому, что ученые меньше внимания будут уделять содержанию исследований и больше внимания - маркетингу. В результате происходит принципиальная смена характера отношений в научных коллективах: 
снижается уровень доверия между учеными, ответственность, способность к самоконтролю качества. В итоге наука теряет свою инновационность и сосредотачивается на вопросах непосредственной полезности. Рыночная экономика в науке жестко изменяет критерии оценки научного продукта: теоретическая ценность и общечеловеческая значимость научного продукта заменяются стандартными количественными показателями. В России сейчас как раз наблюдается пик подобного замещения, что приводит к настоящей гонке за различными библиометрическими показателями, их не всегда честным наращиванием.

K. Vermeir считает, что для сферы научной деятельности более эффективной будет не рыночная экономика, а «подарочная» экономика (gift economy), которая позволяет поддерживать свободу, идеализм, доверие в научном сообществе и между учеными и государством, и существовать на основе нравственных принципов и норм науки. Возможны и переходные, гибридные формы экономики. Важно, чтобы эти гибридные формы взяли все лучшее, а не все худшее, от рыночной и от подарочной экономики.

Не менее важную проблему представляет собой мотивация научной деятельности. В данном аспекте мы бы хотели обратиться к работам отечественных авторов. Обычно, при исследовании мотивации научной деятельности психологи апеллируют к нескольким видам мотивации: внешней и внутренней, мотивации достижений, и именно эти мотивы расцениваются как основные, а часто и единственные в научной деятельности. Однако очевидно, что и деятельность ученого и деятельность других сотрудников детерминирована значительно большим числом мотивов. В своей концепции Т.В. Разина рассматривает десять мотивационных субсистем, или групп мотивов, которые так или иначе, в разных сочетаниях, воздействуют на научную деятельность [23]:

1. Это субсистема внешней мотивации, объединяющая такие мотивы, как высокое положение, статус, степени, звания, должности, материальный достаток, а также социальные обязательства и определенные личностные характеристики - честолюбие, гордость.

2. Субсистема внутренней мотивации обусловлена удовольствием от процесса научного исследования, который является целью, смыслом жизни ученого, дает ощущение полноты бытия.

3. Субсистема мотивации достижений - желание достигать максимальных конечных результатов, решать сложные нетривиальные научные задачи, искать решения неразрешимых проблем.

4. Субсистема мотивации безопасности в научной деятельности включает желание избежать неудач, не быть отторгнутым научным социумом и находиться в стабильном положении в научном коллективе. 
5. Субсистема мотивации конкуренции - желание научного первенства в коллективе в сочетании с нейтрализацией соперников в достижении цели. Проявляется как на межличностном уровне, так и на уровне малых и больших групп.

6. Ценностная мотивационная субсистема - совокупность общечеловеческих и научных ценностных ориентаций и идеалов личности, оказывающих смыслообразующее действие в области научной деятельности.

7. Познавательная мотивационная субсистема - любопытство, интерес, наслаждение познавательными усилиями, направленность на получение принципиально новых знаний.

8. Субсистема антимотивации - мотивация преодоления, когда стимулирующее действие оказывают внешние (сопротивление исследуемого материала, природы) или внутренние (собственные психологические особенности - черты личности и т. п.) условия, затрудняющие реализацию научной деятельности.

9. Рефлексивная мотивационная субсистема - самоконтроль и самостимуляция в научной деятельности.

10. Косвенная мотивационная субсистема предполагает достижение ненаучных целей с помощью научной деятельности.

Автор отмечает, что мотивация научной деятельности представляет собой сложную систему, которая имеет метасистемную обусловленность. Соответственно, в каждый конкретный момент времени научная деятельность сотрудника может быть детерминирована не одним или двумя мотивами, а несколькими, ряд из которых имеет приоритетное значение. Система мотивации также обладает тремя временными уровнями, в соответствии с ситуативными целями, целями, поставленными на ближайшее будущее, и дальними, перспективными целями. Достижение этих целей может быть обеспечено совершенно различными мотивами. Однако если система мотивации обладает высоким уровнем когерентности, иерархична и непротиворечива, то конфликта мотивов не возникает, поскольку система обладает свойством самоорганизации и саморегуляции. Но, как отмечает автор, в ряде случаев система мотивации научной деятельности может разрушаться, ослабляются ее внутрисистемные связи, и это приводит к рассогласованию мотивов и в конечном итоге - к снижению продуктивности научной деятельности или ее полному прекращению. Предложенная автором концепция позволяет на теоретическом уровне объяснить многие феномены и закономерности научной деятельности. Однако в плане психологического обеспечения кадровой работы важно подчеркнуть несколько аспектов ее использования.

Установив полный перечень актуальных и потенциальных мотивов научного сотрудника в тот или иной промежуток времени, мы получаем более 
полную картину о возможностях его персонального стимулирования или о причинах его низкой эффективности. На этой основе можно разрабатывать индивидуальные системы стимулирования научного труда в организации. Очевидно, что специфика организации, в которой работает сотрудник, будет накладывать отпечаток на его мотивационную систему. В этом отношении диагностика системы мотивации могла бы быть эффективной при осуществлении процедур профотбора и организации профессионального обучения. Поскольку концепция была построена автором на отечественной выборке, проблемы перенесения, ее трансформации с учетом особенностей российского менталитета не существует, что значимо повышает ценность данного труда в контексте психологического обеспечения кадровой работы.

Близко к проблеме и задаче диагностики мотивации в кадровой работе примыкает проблема стимулирования научной деятельности. В нашей стране самыми распространенными формами стимулирования научного труда были и остаются материальные средства. Однако не всегда материальный стимул, который научный сотрудник получает после выполнения работы, оказывается действенным, и в первую очередь в отношении генерации новых идей и т. п. В этом отношении за рубежом существует ряд подходов и концепций создания специфических творческих сред, применение которых в научноисследовательских организациях стимулирует творческую активность.

Коллектив авторов во главе c I. Nonaka $[24,25]$ разработал динамическую теорию создания знаний в организации, посредством которой они объясняют, каким образом в любой организации могут появляться, создаваться новые знания. Авторы рассматривают данную теорию как универсальную, т. е. применимую к любой организации. Соответственно, используя ее основные положения, в любой организации можно создать творческую среду. В рамках теории создана трехкомпонентная модель, которая состоит из трех элементов: процесса SECI, предполагающего создание знаний из явной и неявной информации, Ва - как общего фона, контекста для создания знаний (среды), и результатов, т. е. полученных знаний. Процесс возникновения знания происходит по спирали, которая развивается при наличии трех данных компонентов по законам диалектики. Знания могут быть «явные», которые можно зафиксировать, и «неявные» - интуиция, предчувствия и т. п. Новое знание возникает посредством взаимодействия явного и неявного знания. Авторы выделяют четыре режима такого взаимодействия: социализацию, экстернализацию, сочетание и интернализацию.

При этом большую роль в появлении новых знаний играет взаимодействие с внешней средой, обмен информацией с ней. Нужно отметить, что в качестве теоретической основы для разработки данной теории японские авторы берут культурно-историческую концепцию Л.С. Выготского, используя такие 


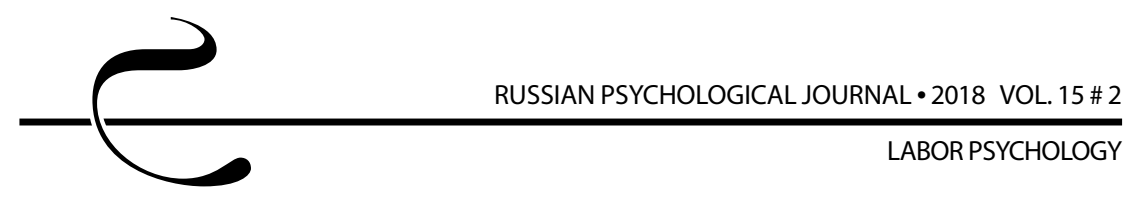

понятия, как «интернализация» и «экстернализация». Это дает основания для эффективного использования динамической теории создания знаний в организации в России.

Другими принципиально важными качествами являются характеристики среды в организации, которая может быть ориентирована на происходящее, диалог, систематизацию и осуществление. Среда также характеризуется двумя измерениями - типом взаимодействия (индивидуальный или коллективный) и характером взаимодействия (непосредственно лично или посредством технологий).

Результатом взаимодействия процессов порождения знания и среды являются базы знаний. Авторы выделяют четыре типа баз знаний. Эмпирические базы знаний состоят по большей части из общих неявных знаний, полученных на основе практического опыта. Концептуальные базы знаний состоят из явного знания, сформулированы с помощью образов, символов и языка. Системные базы знаний состоят из обобщенных, концентрированных знаний. Обыденные базы знаний состоят из неявных знаний, встроенных в повседневную практическую деятельность организации; основная особенность этих знаний - их прикладной характер. Эти четыре типа баз знаний составляют основу, из которой создается новое знание.

В подходе японских коллег основной акцент сделан на том, что знания продуцирует именно организация, а не личность, несмотря на то, что проблеме лидерства также уделено достаточно места. Это заставляет обратить внимание на необходимость формирования научных коллективов и слаженных команд сотрудников. К сожалению, в последние годы формы организации научной деятельности изменились таким образом, что в научных организациях начинают доминировать отношения конкуренции, соперничества, индивидуализма, что обусловлено преобладанием проектной, грантовой формы организации научной деятельности. Это может существенно тормозить процессы создания нового знания.

Порождение знания на индивидуальном уровне авторы трактуют как самотрансценденцию, в процессе которой человек выходит за границы своего существования, бытия. Причем конечный продукт этого процесса (новые знания) может сформироваться только в контакте со средой, с коллективом. Это вполне оправдано, поскольку именно включаясь в канву общечеловеческих знаний, новая информация трансформируется в научные знания, приобретает свою ценностно-смысловую окраску.

Продолжая рассматривать концепции творческих сред, необходимо отметить вариант, изложенный в работе A.P. Wierzbicki, Y. Nakamori [26], которые исследуют влияние широкой социально-культурной среды и более узкой предметной научной среды на процессы научного творчества. 
В ходе их исследований установлены существенные различия в моделях, механизмах и мотивах создания знаний в академических институтах и в коммерческих организациях, создающих наукоемкие продукты. Также имеются различия в способе создания и обоснования знания в трех отраслях: в естественных и фундаментальных науках, в социальных и гуманитарных науках, в технологиях. В отечественном науковедении этот вопрос также рассматривался, но на философском уровне, а не на психологическом.

Авторы исследовали особенности создания творческой среды для научно-исследовательского процесса, который протекает в основном в академических кругах или коммерческих научно-исследовательских лабораториях. Особенностью данной творческой среды был ее виртуальный характер. Предварительные исследования на выборке студентов и аспирантов показали, что основные условия, необходимые для стимуляции творчества, - это обучение подготовке и проведению экспериментов, помощь и руководство от более опытных коллег и частое общение внутри группы, в том числе и критические замечания.

A.P. Wierzbicki, Y. Nakamori предлагают три модели создания нового знания:

1. Герменевтика: представляется как развертывание спирали «просвещение - анализ - погружение - отражение» и представляет собой самую индивидуализированную часть научного поиска, выполняется каждым ученым и предполагает чтение литературы, последующее осмысление или формирование неких неявных знаний.

2. Дебаты: развертывающаяся спираль «просвещение - дебаты - погружение - выбор», когда происходит обсуждение тех неявных интуитивных знаний, которые есть у группы.

3. Эксперимент: также представляет собой спираль «просвещение эксперимент - интерпретация - выделение». Эта спираль показывает, как создаются знания в индивидуальном исследовательском эксперименте.

Эти три спирали могут быть объединены в одну тройную спираль, которая демонстрирует, как создаются знания в научных организациях. Данные спирали разворачиваются в специально организованной креативной среде, состоящей из нескольких подсистем и инструментов, таких как, например, электронные библиотеки, базы ссылок, специальные программы с «умным» интерфейсом, поисковые веб-системы, которые могут анализировать тексты. Разрабатываются специальные программные продукты для осуществления дебатов в виртуальной среде и т. п.

\section{Обсуждение результатов}

Что касается России, практика подготовки научных кадров в специализированных школах существовала во времена СССР и продолжает существовать 


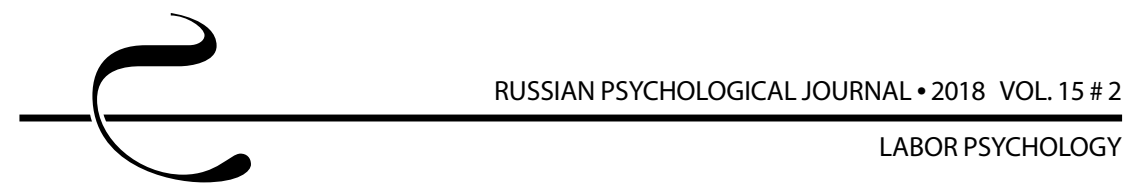

и сейчас. Хорошо известны школы для одаренных детей при МФТИ и при многих других ведущих вузах России. Однако вопрос о том, какой процент учащихся данных школ становится научными работниками, не изучался. Проблема состоит и в качестве образования, поскольку в ряде случаев такие школы ориентированы не на подготовку научных кадров, а на подготовку детей к сдаче ЕГЭ и последующему поступлению в вуз. В любом случае, в силу недостаточной социально-политической стабильности современной России и возрастающих эмиграционных намерений российских научных кадров, данный путь не может быть пока признан эффективным.

Если анализировать пики творческой продуктивности научных работников в России, здесь нам важны два аспекта. Во-первых, на отечественной почве второй пик, на наш взгляд, будет наступать позднее, что связано с определенной установкой на необходимость двух защит (кандидатской и докторской). Если за рубежом научный сотрудник может ощущать себя полноценным членом научного сообщества после получения $\mathrm{PhD}$, то в России, в связи со значительной девальвацией научных степеней, ученому, чтобы получить относительную научную самостоятельность и независимость, нужно защитить кандидатскую и докторскую диссертации. И если пик продуктивности у зарубежных научных сотрудников наступает через несколько лет после получения PhD, то в России - за несколько лет до защиты докторской диссертации. В среднем, это возраст 40-45 лет. Во-вторых, следствием этого должна быть определенная смена стратегий региональной и государственной поддержки ученых. Сейчас большинство программ поддержки касается молодых ученых (до 35 лет). На наш взгляд, необходимо также оказывать помощь исследователям на втором пике их творческой продуктивности. Второй пик творческой продуктивности, с нашей точки зрения, в условиях России будет более результативен в плане научных продуктов в силу сочетания трех факторов: высокой мотивации (вызванной желанием защиты докторской диссертации и перехода в новый научный статус), значительным опытом научной работы и осведомленности в своей научной отрасли, а также достаточным количеством психофизических ресурсов, которые уже в меньшей степени тратятся на решение бытовых, личных и прочих, не связанных с научной деятельностью, вопросов. Тем не менее, представляется крайне важным проведение эмпирических исследований пиков творческой продуктивности у российских ученых.

На наш взгляд, принципы рыночной экономики в российской науке вполне применимы в коммерческих наукоемких производствах или лабораториях, которые обслуживают конкретный заказ или технологический процесс. В научно-исследовательских институтах, особенно осуществляющих фундаментальные исследования, подарочная экономика будет наиболее оправданной, 
хотя, безусловно, элементы рыночной экономики будут присутствовать и там. Что касается научной деятельности, осуществляемой в вузах (не учитывая МИПы) то тут коммерциализация науки будет не только невыгодна, но и вредна. Сотрудники данных организаций и так вынуждены осуществлять параллельно две принципиально различных по психологической структуре деятельности (учебную и научно-исследовательскую), что требует от них работы на пределе возможностей. Коммерциализация науки предполагает осуществление еще и третьего вида деятельности, что неизбежно приведет к информационным перегрузкам, и, как следствие, к снижению качества научной деятельности или, что еще хуже - к ее симуляции.

На наш взгляд, хоть динамическая теория создания знаний в организации и имеет российские теоретические основы, ее использование применительно к научно-исследовательским организациям может быть довольно ограничено. В данном случае тормозом для ее внедрения будут своеобразные традиции в осуществлении научно-исследовательской работы в организациях, носителями и хранителями которых являются научные сотрудники старшего поколения. С этой позиции внедрение таких творческих сред может быть оптимально в молодежных научных группах, CHO, в школах для одаренных детей при вузах. Возможно применение принципов творческих сред и в коммерчески-ориентированных наукоемких организациях. Стоит, однако, отметить, что в данном случае прямое внедрение описанных подходов также будет недопустимо, поскольку концепция разрабатывалась для широкого круга организаций, и в отношении научно-исследовательских организаций ее необходимо конкретизировать.

Нужно отметить, что когда А.P. Wierzbicki, Y. Nakamori создавали свою методику, описанные технологии были еще не так широко распространены не только в России, но и за рубежом. Сейчас, безусловно, все эти вещи имеются в любом вузе, однако, как показывает практика, они не работают на том уровне, который предлагают японские авторы. Это может создать обманчивое впечатление, что данная технология не будет работать в России. Специфика состоит в том, что в описываемой модели применение подобных технологий системно, логично, практически непрерывно, хорошо отлажено и не требует временны́ затрат на организацию данных процессов. В отечественных организациях еще достаточно типичной является ситуация, когда дорогостоящее оборудование простаивает из-за отсутствия должного технического обслуживания, бюрократических сложностей в использовании этой аппаратуры, отсутствия навыков и опыта работы с ним у широкого круга потенциальных пользователей, а также в силу того, что данный способ общения и взаимодействия пока еще не является типичным для российской ментальности. Пока в научно-исследовательской работе отечественных 


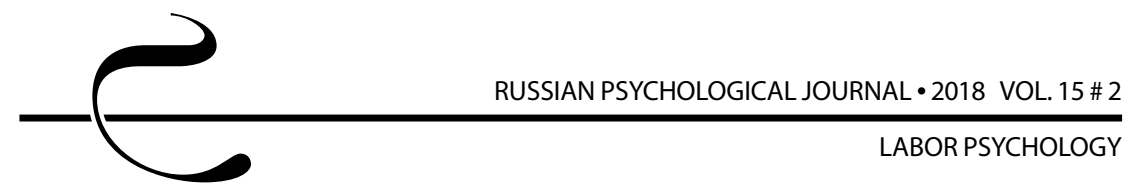

ученых доминирует тенденция к непосредственному общению с коллегами. К виртуальным контактам они прибегают лишь в случае невозможности личного контакта.

Таким образом, технически сейчас нет особых сложностей для внедрения в научных организациях такого рода творческих сред. Однако российское научное сообщество еще не готово к этому, и в силу данных причин подобные технологии в среде российских ученых вряд ли будут достаточно эффективны.

Однако, с усовершенствованием технологий и технических устройств мобильной связи (появлением смартфонов и т. п.) не только в среде российских ученых, но и в большинстве иных профессиональных сред подобные сетевые модели взаимодействия возникают стихийно, спонтанно. Однако творческий потенциал такого рода сред и возможности управления процессами в них не исследовались ни в России, ни за рубежом, что представляет собой крайне перспективное направление исследований.

Нужно отметить, что и виртуальные, сетевые научные организации в России встречаются значительно реже, чем в Европе, странах Америки и Азии. Отчасти это было связано с тем, что на протяжении последних 25 лет российское общество решало проблему удержания своих научных кадров, а не их привлечение из других стран, в том числе и виртуальное. Тем не менее, подобные организации появляются, и в ближайшем будущем число их должно возрасти. Необходимо отметить ряд отличий в психологическом сопровождении кадровой работы, который может возникнуть в виртуальных организациях. Несмотря на достаточно высокий интерес к менеджменту сетевых организаций за рубежом, единой теории или концепции не выработано. Существуют отдельные исследования, которые отражают ряд закономерностей функционирования виртуальных организаций. Так, в работе M. R. Lee показано, что основные закономерности проявления лидерства и его механизмы в виртуальных организациях будут иными [27]. Несмотря на то, что психологическая дистанция у членов виртуальных коллективов достаточно велика, она может положительно влиять на эффективность деятельности [28]. Как показали F. Pangl и J.M. Chan [29], эффективность команды положительно связана с доверием и обменом знаниями, что согласуется с упомянутой ранее теорией создания знаний в организации I. Nonaka. Подобного рода закономерностей за последние несколько лет установлено довольно много. Необходимость их обобщения и систематизации приводит к появлению различных эмпирических моделей, таких как, например, матрица TOWS [30], или математических моделей, созданных с помощью процедур структурного моделирования [31]. В любом случае, при кадровом обеспечении виртуальных организаций в России, в том числе научных, необходим всесторонний 
учет специфики функционирования именно виртуальных организаций, специфики российского менталитета и особенностей профессиональной деятельности в научной сфере.

\section{Заключение}

Таким образом, в данной работе мы рассмотрели ряд теоретических подходов к исследованию психологического обеспечения управления кадровой работой в научной организации в России на современном этапе. Было установлено, что несмотря на слабую теоретическую и практическую разработку данного вопроса, существует достаточное количество теорий и теоретических моделей, способных стать методологической основой для организации кадровой работы в научном коллективе.

Основной проблемой, которая требует своего учета при осуществлении психологического сопровождения кадровой работы в научной организации, является наличие этнонациональной и культурной специфики, носителями которой являются представители старшего поколения ученых. Другой проблемой научных организаций в России является достаточно ограниченное (по сравнению с научными организациями в странах Европы и Америки) использование информационных технологий. Третьей проблемой является отсутствие социально-экономической и политической стабильности в стране, что накладывает существенный отпечаток на деятельность научных организаций. Именно эти три особенности делают неэффективным прямой перенос зарубежных теоретических моделей психологического обеспечения различных аспектов кадровой работы на российскую почву. Также важно учитывать тип научной организации в отношении содержания деятельности (теоретическая или прикладная), особенностей финансирования (бюджетное государственное финансирование, коммерческая организация, смешанные формы). В рамках этих организаций научно-исследовательская деятельность может выступать как основная профессиональная деятельность для сотрудника или же как неосновная, дополнительная.

Существующие отечественные теории могут стать основой для осуществления кадрового сопровождения деятельности научной организации, однако их пока крайне не достаточно, и это направление является перспективным в плане развития психологии менеджмента.

\section{Литература}

1. Feist G. J. The psychology of scientific thought and behavior //The Psychologist. 2013. Vol. 26, № 12. P. 864-867.

2. Mehtap Ö., Kökalan Ö. Prevailing organizational identity strength: the relationship between identity, justice perceptions and organizational citizenship 
behavior // International Journal of Social Sciences and Humanity Studies. 2014. Vol. 6, Issue 1. P. 32-46.

3. Muppidathi P., Krishnan V. R. Effect of transformational leadership on followers' collective efficacy and group cohesiveness: social identity as mediator // Humanities and Social Sciences Review. 2015.04 (03).P. 363-372. URL: http:// www.rkvenkat.org/mythili.pdf (Accessed 11.05.2018).

4. Gibson D. S., Thompson C. B., Neill U. S. Assessing Research Productivity //The Scientist. 2015. January 1. URL: http://www.the-scientist.com/?articles.view/ articleno/41682/title/Assessing-Research-Productivity/ (Accessed 25.01.2018).

5. Sørensen H.T. I-determinants for a successful PhD or postdoctoral outcome // Clinical Epidemiology. 2016. Vol. 8. P. 297-303. DOI: $10.2147 / C L E P . S 110527$

6. van der Lee R., Ellemers $N$. Gender contributes to personal research funding success in The Netherlands // PNAS. 2015. Vol. 112, № 40. P. 12349-12353. DOI: $10.1073 /$ pnas. 1510159112

7. Albert C., Davia M. A., Legazpe N. Determinants of Research Productivity in Spanish Academia // European Journal of Education. 2016. Vol. 51, Issue 4. P. 535-549. DOI: $10.1111 /$ ejed.12142

8. Antonio-García M. T., López-Navarro l., Rey-Rocha J. Determinants of success for biomedical researchers: a perception-based study in a health science research environment // Scientometrics. 2014. Vol. 101, Issue 3. P. 1747-1779. DOI: $10.1007 / \mathrm{s} 11192-014-1376-6$

9. Гайдамашко И. В., Кандыбович С. Л., Секач М. Ф. Психология: наука и практика // Психолого-педагогический поиск. 2017. № 4 (44). C. 65-74. URL: http:// ppsjournal.rsu.edu.ru/wp-content/uploads/\%D0\%9F\%D0\%9F\%D0\%9F2017-\%E2\%84\%96444.pdf (дата обращения: 25.01.2018).

10. Карро И. И., Попова А. А. Инновационный менеджмент в России // Современные наукоемкие технологии. 2013. № 10-2. С. 263-264.

11. Прохоров А. П. Русская модель управления. М.: Студия Артемия Лебедева, 2014. 496 с.

12. Сидоренков А. В., Коваль Е. С. Взаимосвязь групповых феноменов и социально-психологической адаптации работников в организации // Психологический журнал. 2015. Т. 36, № 1. С. 34-45.

13. Аристер Н. И., Анцупов А. Я., Гайдамашко И. В. и др. Стратегия и практика достижения высшей квалификации субъектом инновационного труда: монография. М.: Буки Веди, 2016. 541 с.

14. Берестнева Е. В. Проблемы оценки исследовательского потенциала // Фундаментальные исследования. 2015. № 2 (19). С. 4151-4153.

15. Войтикова М. А. Влияние эмоционального интеллекта на успешность управления научной организацией // Человеческий капитал. 2017. № 12 (108). С. 36-40. 
ПСИхОЛОГИЯ ТРУДА

16. Гайдамашко И. В., Пугачева Е. В., Цуникова Т. Г. Системно-мыследеятельностный подход к самоорганизации деятельности субъектов образовательного процесса в техническом университете // Человеческий капитал. 2015. № 11-12 (83). С. 20-23.

17. Грязева-Добшинская В. Г. Психология инновационного менеджмента организации. Челябинск: Изд-во ЮУрГУ, 2013. 298 с.

18. Пугачева Е. В. Психологические детерминанты профессиональной надежности сотрудника учреждения высшего профессионального образования // Современная психология. 2013. № 2. URL: http://modernpsy. org/ru/2013/2/5 (дата обращения: 25.01.2018).

19. Аркова Т. А. Научные основы организации научно-исследовательской деятельности студентов в педагогическом вузе // Вестник Челябинского государственного педагогического университета. 2013. № 3. С. 215-228.

20. Feist G. J. The Development of Scientific Talent in Westinghouse Finalists and Members of the National Academy of Sciences // Journal of Adult Development. 2006. Vol. 13, Issue 1. P. 23-35. DOI: 10.1007/s10804-006-9002-3

21. Simonton D. K. Age and Outstanding Achievement: What Do We Know After a Century of Research? // Psychological Bulletin. 1988. Vol. 104, № 2. P. 251-267.

22. Vermeir K. Scientific Research: Commodities or Commons? // Science \& Education. 2013. Vol. 22, Issue 10. P. 2485-2510. DOI 10.1007/s11191-012-9524-y

23. Разина Т. В. Структурно-функциональная организация и генезис мотивации научной деятельности: дисс. ... д. психол. наук. Ярославль, 2016. 612 c.

24. Nonaka l., von Krogh G., Voelpel S. Organizational Knowledge Creation Theory: Evolutionary Paths and Future Advances // Organization Studies. 2006. Vol. 27, Issue 8. P. 1179-1208. DOI: 10.1177/0170840606066312

25. Nonaka I., Toyama R., Konno N. SECl, Ba and Leadership: a Unified Model of Dynamic Knowledge Creation // Long Range Planning. 2000. Vol. 33, Issue 1. P. 5-34. DOI: 10.1016/S0024-6301(99)00115-6

26. Creative environments: Issues of Creativity Support for the Knowledge Civilization Age / A. P. Wierzbicki, Y. Nakamori (Eds.). Berlin, Heidelberg: Springer, 2007. 509 p. DOI: 10.1007/978-3-540-71562-7

27. Lee M. R. Leading Virtual Project Teams: Adapting Leadership Theories and Communications Techniques to 21st Century Organizations. 1st ed. Boca Raton: CRC Press, 2013. 217 p.

28. Magnusson P., Schuster A., Taras V. A Process-Based Explanation of the Psychic Distance Paradox: Evidence from Global Virtual Teams // Management International Review. 2014. Vol. 54, Issue 3. P. 283-306. DOI: $\underline{10.1007 / s 11575-014-0208-5}$ 


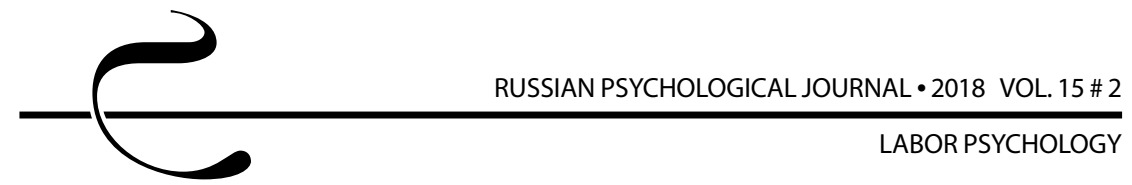

29. Pangil F., Chan J. M. The mediating effect of knowledge sharing on the relationship between trust and virtual team effectiveness // Journal of Knowledge Management. 2014. Vol. 18, Issue 1. P. 92-106. DOI: 10.1108/JKM-09-2013-0341

30. Morley S., Cormican K., Folan P. An Analysis of Virtual Team Characteristics: A Model for Virtual Project Managers // Journal of Technology Management \& Innovation. 2015. Vol. 10, № 1. P. 188-203. DOI: $10.4067 / S 0718-27242015000100014$

31. Merkevičius J., Davidavičienè V., Raudeliūnienè J., Buleca J. Virtual organization: specifics of creation of personnel management system // E\&M Economics and Management. 2015. Vol. 18, Issue 4. P. 200-211. DOI: 10.15240/tul/001/2015-4-014

\section{References}

1. Feist G. J. The psychology of scientific thought and behavior. The Psychologist, 2013, V. 26, no. 12, pp. 864-867.

2. Mehtap Ö., Kökalan Ö. Prevailing organizational identity strength: The relationship between identity, justice perceptions and organizational citizenship behavior. International Journal of Social Sciences and Humanity Studies, 2014, V. 6, Issue 1, pp. 32-46.

3. Muppidathi P., Krishnan V. R. Effect of transformational leadership on followers' collective efficacy and group cohesiveness: Social identity as mediator. Humanities and Social Sciences Review, 2015, no. 04 (03), pp. 363-372. Available at: http://www.rkvenkat.org/mythili.pdf (Accessed 11 May 2018).

4. Gibson D. S., Thompson C. B., Neill U. S. Assessing research productivity. The Scientist, 2015, January 1. Available at: http://www.the-scientist.com/?articles. view/articleno/41682/title/Assessing-Research-Productivity/ (Accessed 25 January 2018).

5. Sørensen H.T. I-determinants for a successful PhD or postdoctoral outcome. Clinical Epidemiology, 2016, V. 8, pp. 297-303. DOI: $10.2147 /$ CLEP.S110527

6. van der Lee R., Ellemers N. Gender contributes to personal research funding success in The Netherlands. PNAS, 2015, V. 112, no. 40, pp. 12349-12353. DOI: $10.1073 /$ pnas.1510159112

7. Albert C., Davia M. A., Legazpe N. Determinants of research productivity in Spanish Academia. European Journal of Education, 2016, V. 51, Issue 4, pp. 535-549. DOI: $10.1111 /$ ejed.12142

8. Antonio-García M. T., López-Navarro l., Rey-Rocha J. Determinants of success for biomedical researchers: A perception-based study in a health science research environment. Scientometrics, 2014, V. 101, Issue 3, pp. 1747-1779. DOI: $10.1007 /$ s11192-014-1376-6 
9. Gaidamashko I. V., Kandybovich S. L., Sekach M. F. Psychology: Theory and practice. Psychological and Pedagogical Search, 2017, no. 4 (44), pp. 65-74. Available at: http://ppsjournal.rsu.edu.ru/wp-content/ uploads/\%D0\%9F\%D0\%9F\%D0\%9F-2017-\%E2\%84\%96444.pdf (Accessed 25 January 2018).

10. Karro I. I., Popova A. A. Innovation management in Russia. Sovremennye naukoemkie tekhnologii - Modern High Technologies, 2013, no. 10-2, pp. 263-264 (in Russian).

11. Prokhorov A. P. Russkaya model' upravleniya [The Russian model of management]. Moscow, Studiya Artemiya Lebedeva Publ., 2014. 496 p.

12. Sidorenkov A. V., Koval' E. S. Interrelations between group phenomena and socio-psychological adaptation among employees. Psikhologicheskii zhurnal, 2015, V. 36, no. 1, pp. 34-45 (in Russian).

13. Arister N. I., Antsupov A. Ya., Gaidamashko I.V. Strategiya ipraktika dostizheniya vysshei kvalifikatsii sub"ektom innovatsionnogo truda [The strategy and practice of achieving the highest qualification by the subject of innovative labor]. Moscow, Buki Vedi Publ., 2016. 541 p.

14. Berestneva E. V. Problems of assessing the research potential. Fundamental'nye issledovaniya - Fundamental Research, 2015, no. 2(19), pp.4151-4153 (in Russian).

15. Voitikova M. A. The impact of emotional intelligence on the success of managing scientific organization. Chelovecheskii kapital - Journal of Human Capital, 2017, no. 12 (108), pp. 36-40 (in Russian).

16. Gaidamashko I.V., Pugacheva E.V., Tsunikova T. G. The systemic mental activity approach to activity self-organization among subjects of the educational process at a technical university. Chelovecheskii kapital - Journal of Human Capital, 2015, no. 11-12 (83), pp. 20-23 (in Russian).

17. Gryazeva-Dobshinskaya V. G. Psikhologiya innovatsionnogo menedzhmenta organizatsii [Psychology of the innovative management of organizations]. Chelyabinsk, South Ural State University Publ., 2013. 298 p.

18. Pugacheva E. V. Psychological determinants of professional reliability in members of institutions of higher professional education. Modern Psychology, 2013, no. 2. Available at: http://modernpsy.org/ru/2013/2/5 (Accessed 25 January 2018).

19. Yarkova T. A. Scientific foundations for managing students' research activities in educational institutions of higher education. Vestnik Chelyabinskogo gosudarstvennogo pedagogicheskogo universiteta - Bulletin of Chelyabinsk State Pedagogical University, 2013, no. 3, pp. 215-228 (in Russian).

20. Feist G. J.The development of scientific talent in Westinghouse finalists and members of the National Academy of Sciences. Journal of Adult Development, 2006, V. 13, Issue 1, pp. 23-35. DOI: 10.1007/s10804-006-9002-3 


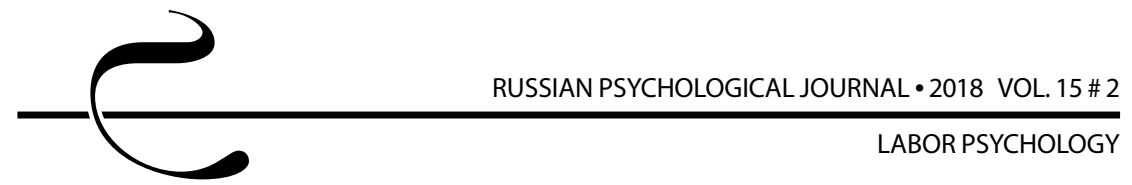

21. Simonton D. K. Age and outstanding achievement: What do we know after a century of research? Psychological Bulletin, 1988, V. 104, no. 2, pp. 251-267.

22. Vermeir K. Scientific research: Commodities or commons? Science \& Education, 2013, V. 22, Issue 10, pp. 2485-2510. DOI: 10.1007/s11191-012-9524-y

23. Razina T. V. Strukturno-funktsional'naya organizatsiya i genezis motivatsii nauchnoi deyatel'nosti [Structural and functional organization and the genesis of scientific activity motivation]. Diss. Dr. Sci. (Psych.). Yaroslavl, 2016.612 p.

24. Nonaka I., von Krogh G., Voelpel S. Organizational knowledge creation theory: Evolutionary paths and future advances. Organization Studies, 2006, V. 27, Issue 8, pp. 1179-1208. DOI: 10.1177/0170840606066312

25. Nonaka I., Toyama R., Konno N. SECl, Ba and leadership: A unified model of dynamic knowledge creation. Long Range Planning, 2000, V. 33, Issue 1, pp. 5-34. DOI: 10.1016/S0024-6301(99)00115-6

26. Wierzbicki A. P., Nakamori Y. (eds.) Creative environments: Issues of creativity support for the knowledge civilization age. Berlin, Heidelberg, Springer, 2007. 509 p. DOI: $10.1007 / 978-3-540-71562-7$

27. Lee M. R. Leading virtual project teams: Adapting leadership theories and communications techniques to 21st century organizations. Boca Raton, CRC Press, 2013. $217 \mathrm{p}$.

28. Magnusson P., Schuster A., Taras V. A process-based explanation of the psychic distance paradox: Evidence from global virtual teams. Management International Review, 2014, V. 54, Issue 3, pp. 283-306. DOI: 10.1007/s11575-014-0208-5

29. Pangil F., Chan J. M. The mediating effect of knowledge sharing on the relationship between trust and virtual team effectiveness. Journal of Knowledge Management, 2014, V. 18, Issue 1, pp. 92-106. DOI: 10.1108/JKM-09-2013-0341

30. Morley S., Cormican K., Folan P. An analysis of virtual team characteristics: A model for virtual project managers. Journal of Technology Management \& Innovation, 2015, V. 10, no. 1, pp. 188-203. DOI: 10.4067/S0718-27242015000100014

31. Merkevičius J., Davidavičienè V., Raudeliūnienè J., Buleca J. Virtual organization: Specifics of creation of personnel management system. E\&M ECOnomics and Management, 2015, V. 18, Issue 4, pp. 200-211. DOI: 10.15240/ tul/001/2015-4-014 